\title{
Study on the Relationship between Postgraduate Student's Emotion Regulation and Commit Suicide Attitude
}

\author{
Tingting Luo ${ }^{1,2 *}$, Lin Lu${ }^{1}$, Xintian Zhu ${ }^{1}$ \\ ${ }^{1}$ Culture and Social Development Study School of Southwest University, Chongqing, China \\ ${ }^{2}$ Center for Studies of Economic and Social Development, Southwest University, Chongqing, China \\ Email:
}

Received 13 April 2015; accepted 27 June 2015; published 30 June 2015

Copyright (C) 2015 by authors and Scientific Research Publishing Inc.

This work is licensed under the Creative Commons Attribution International License (CC BY). http://creativecommons.org/licenses/by/4.0/

(c) (i) Open Access

\begin{abstract}
Aim: The high degree of group commit suicide phenomenon had been a social concern. The purpose of this paper was to try to understand how emotion regulation affected suicide attitude in graduate students. Method: 406 postgraduates in three universities of Chongqing were tested with Emotion Regulation Questionnaire (ERQ) and Suicide Attitude Questionnaire (QSA). Results: On the emotion regulation side, there were significant gender differences in revealing, and significant grade differences in rumination. When encountered with negative emotion, avoidance and suppression happened much more frequently than rumination and revealing. The latter two happened more frequently when postgraduates encountered positive emotions. On the suicidal attitude side, there were significant grade and professional differences in attitudes towards the suicide victims' families and significant grade differences in euthanasia attitudes. Correlation analysis and regression analysis showed that suppressing negative emotion and avoiding positive emotion were important variables to affect graduate suicide attitude. Conclusion: Inappropriate emotional regulation might be an important reason for the postgraduates who approved of suicide.
\end{abstract}

\section{Keywords}

Graduate Students, Emotion Regulation, Suicide Attitude

\section{Introduction}

In recent years, postgraduate commit suicide cases had frequently appeared in newspapers; commit suicide had

${ }^{*}$ Corresponding author.

How to cite this paper: Luo, T. T., Lu, L., \& Zhu, X. T. (2015). Study on the Relationship between Postgraduate Student's Emotion Regulation and Commit Suicide Attitude. Creative Education, 6, 1237-1243.

http://dx.doi.org/10.4236/ce.2015.611122 
become one of the main causes of postgraduate students' death (Wang, 2012). According to a survey made by the Chongqing University mental health education and consultation center about a university postgraduate commit suicide case (commit suicide attempted, and commit suicide death), the statistics result was 11 cases in 2011 , 13 cases in 2012, 14 cases in 2013, and an annual average of 12.7 cases. According to the Chongqing Three Gorges central psychological counseling statistics, the number of postgraduate students in China commit suicide was about 2000; about 1000 commit suicide attempters received medical treatment every year (Chiles \& Strosahl, 1995). The high degree of group commit suicide phenomenon had been a social concern.

\section{Literatures Review}

Most researchers believed that, there was a close relation between attitude and behavior about commit suicide, to a certain extent, the individual attitude to commit suicide was a key factor in the implementation of commits suicide behavior (Jing et al., 2008). Commit suicide attitude was a kind of persistent and consistent tendency, which was affected by cultural traditions, customs, religious, legal and other factors. It reflected the inherent tendency of individuals in the psychological stress situation commit suicide implementation behavior. Therefore, identifying the factors which influences postgraduates commit suicide attitude, behavior had important significance on the prevention of commit suicide act (Xie et al., 2012). At present, most of the researches related to domestic commit suicide attitude influence factors were undergraduate students, mainly related to gender, grade, major demographic variables and social support, coping style, commit suicide ideas factors. In this study, taking emotion regulation, which was closely related with people's psychological health, as a starting point, to study the effect of emotion regulation mode of postgraduate students' commit suicide attitude.

In the field of psychology, scholars had different definitions on emotion regulation. Gross deemed that emotion regulation was a process that the body influences emotional types, occurrence time, experience and expression positively. Thompson thought emotion regulation referred to in order to complete the goal, one's emotional inner and external reaction monitoring, evaluation and amendment process (Han \& Zhang, 2014). In Huang Miner's opinion, emotion regulation referred to the individual through certain regulation strategy and mechanism, to manage and change themselves (or others) emotional process, while the subjective feeling, the expression and action, physiological reaction had some change. Contrast found that Huang's emotion regulation theory had a certain similarity to the above theory, but quantified the emotion regulation from the subjective feeling, the expression and action, physiological reaction. And that the theory was close to the Chinese culture.In this study, based on the theory of Huang Miner's emotion regulation (Liu et al., 2011), through the questionnaire survey method, selected postgraduate group as the research object, to explore the relationship of emotion regulation and commit suicide attitude, to provide the base for postgraduates' prevention and psychological treatment.

\section{Method}

\subsection{Participants}

The survey was administered to 500 graduate students of three universities in Chongqing city, 406 valid questionnaires, what average age was 25 years old: $37 \%$ female and $63 \%$ male; $56 \%$ science students and $44 \%$ arts students; 35\% higher grades and 65\% lower grades (Luo et al., 2004).

\subsection{Research Means}

Emotion Regulation Questionnaire (ERQ) and the scale were made by Gross (2002), and Huang Miner combined with the actual revision. The questionnaire had 50 questions, five dimensions, which was ignored regulation, inhibition regulation, attention regulation, catharsis regulation and natural regulation partly.

Using 5 point scoring, from "never happened" to "happen" were recorded as $1-5$ points, the higher the score that individuals adopt some emotion regulation mode for higher frequency, had a high reliability and validity. The questionnaire included positive emotions (happiness, interest) and negative emotional (pain, guilt, sadness, disgust, anger, shy, shame and fear). In this study, the total scale coefficient was 0.89 , the five dimensions of $\alpha$ coefficient was above 0.61. Huang Miner divided emotion regulation into increased regulation (attention, catharsis) and attenuated type adjustment (ignore, suppress), reason adjustment (ignore, attention) and response regulation (inhibition, catharsis). In view of this, this study mainly discussed in the positive, negative emotion, the relationship between postgraduate subjects' commit suicide attitude and ignored regulation, inhibition regu- 
lation, attention regulation, catharsis regulation (Gross, 2002).

Commit suicide attitude questionnaire (QSA) of the scale by Xiao et al. (1999) prepared was proved having high reliability and validity. The questionnaire includes 29 questions, divided into four dimensions: knowledge of commit suicide character of the Act (F1), the attitude of commit suicides (F2), to the families of those suicides (F3) attitude, attitude to euthanasia (F4). Using 5 point scoring, from "fully agree with" to "completely don't agree with" were recorded as 1 - 5 points. The calculation of each dimension of the problem scores, according to the score of attitude can be divided into three kinds commit suicide act 2.5 divided into positive, recognition, understanding and tolerance of the commit suicide act attitude; 2.5 - 3.5 contradictory or neutral attitude, >3.5 was regarded as commit suicide opposition (Thompson, 1991), denial, rejection and discrimination attitude. In this study, the total scale $(\mathrm{F})$ and the $\alpha$ coefficient was 0.84 , all dimensions of $\mathrm{C}$ coefficient was above 0.60 .

\subsection{Data Handling}

Using SPSS11.5 for data processing and analysis, statistical methods mainly include the $t$ test, correlation analysis, and multiple linear regression analysis.

\section{Results}

\subsection{Postgraduate Students' Emotion Regulation Differences in Demographic Variables}

In gender, grade and major variables for postgraduate students, emotion adjustment of each dimension did the $t$ test. The results showed, variable effects on the postgraduate students emotion regulation were smaller; but the boys and girls in the catharsis adjustment dimension difference was significant, $\mathrm{t}=3.46, p<0.01$; masters on high, low grade students were significantly, regulating differences in attention to $t=2.11, p<0.05$. See details in Table 1.

\subsection{Differences Comparison among the Postgraduate Students, in the Positive and Negative Emotion Four Types}

According to the study of Xin Yong, Li Hong et al., negative sentiment weakened individual behavior control ability, positive emotions were opposite. Therefore, postgraduates in positive, negative emotion regulation styles and the choice of behavior mode were closely related. In the positive, negative emotions, respectively for weakening regulation and increased regulation, regulating and adjusting the reasons reflect on paired $t$ test, the results found, in positive emotion, attenuated type adjustment (ignore and inhibit) was significantly lower than the enhanced adjustment (rumination and revealing), $\mathrm{t}=-8.32, p<0.001$; in negative emotion regulation, attenuated significantly higher than that of increased regulation, $\mathrm{t}=8.06, p<0.001$; and the graduate student participants in the positive (Huang \& Guo, 2000), negative emotion, reason adjustment (ignore and attention) were significantly higher than the response regulation (restraint and catharsis), $(\mathrm{t}=3.67, p<0.001 ; \mathrm{t}=2.95, p<0.01$ ), saw details in Table 2.

Table 1. Postgraduate students' emotion regulation differences in demographic variables $(n=406)$.

\begin{tabular}{|c|c|c|c|c|c|c|c|c|c|c|c|c|c|}
\hline & & \multicolumn{3}{|c|}{ Ignore adjustment } & \multicolumn{3}{|c|}{ Inhibition adjustment } & \multicolumn{3}{|c|}{ Attention adjustment } & \multicolumn{3}{|c|}{ Catharsis adjustment } \\
\hline & & $\mathrm{M} \pm \mathrm{S}$ & $\mathrm{t}$ & $p$ & $\mathrm{M} \pm \mathrm{S}$ & $\mathrm{t}$ & $p$ & $\mathrm{M} \pm \mathrm{S}$ & $\mathrm{t}$ & $p$ & $\mathrm{M} \pm \mathrm{S}$ & $\mathrm{t}$ & $p$ \\
\hline \multirow[b]{2}{*}{ Gender } & Boy & $3.07 \pm 0.56$ & \multirow[b]{2}{*}{0.53} & \multirow[b]{2}{*}{0.958} & $2.8 \pm 0.46$ & \multirow[b]{2}{*}{0.60} & \multirow[b]{2}{*}{0.551} & $2.78 \pm 0.49$ & \multirow[b]{2}{*}{1.38} & \multirow[b]{2}{*}{0.166} & $2.83 \pm 0.44$ & \multirow[b]{2}{*}{3.46} & \multirow[b]{2}{*}{0.001} \\
\hline & Girl & $3.07 \pm 0.55$ & & & $2.9 \pm 0.53$ & & & $2.85 \pm 0.56$ & & & $2.99 \pm 0.51$ & & \\
\hline \multirow[b]{2}{*}{ Major } & Science & $3.07 \pm 0.57$ & \multirow[b]{2}{*}{0.06} & \multirow[b]{2}{*}{0.949} & $2.88 \pm 0.49$ & \multirow[b]{2}{*}{1.36} & \multirow[b]{2}{*}{0.180} & $2.82 \pm 0.53$ & \multirow[b]{2}{*}{1.29} & \multirow[b]{2}{*}{0.199} & $2.89 \pm 0.48$ & \multirow[b]{2}{*}{0.463} & \multirow[b]{2}{*}{0.643} \\
\hline & Arts & $3.06 \pm 0.53$ & & & $2.78 \pm 0.48$ & & & $2.72 \pm 0.42$ & & & $2.86 \pm 0.42$ & & \\
\hline \multirow{2}{*}{ Grade } & High & $3.07 \pm 0.57$ & \multirow{2}{*}{0.00} & \multirow{2}{*}{0.998} & $2.84 \pm 0.49$ & \multirow{2}{*}{0.80} & \multirow[b]{2}{*}{0.425} & $2.73 \pm 0.47$ & \multirow{2}{*}{2.11} & \multirow[b]{2}{*}{0.035} & $2.85 \pm 0.45$ & \multirow{2}{*}{1.19} & \multirow[b]{2}{*}{0.236} \\
\hline & Low & $3.07 \pm 0.56$ & & & $2.88 \pm 0.47$ & & & $2.85 \pm 0.54$ & & & $2.91 \pm 0.48$ & & \\
\hline
\end{tabular}


Table 2. Differences comparison among the postgraduate students, in the positive and negative emotion four types $(n=406)$.

\begin{tabular}{|c|c|c|c|c|c|c|c|c|}
\hline & $\begin{array}{l}\text { Weaken } \\
\text { regulation }\end{array}$ & $\begin{array}{l}\text { Increased } \\
\text { regulation }\end{array}$ & & \multirow[t]{2}{*}{$p$} & $\begin{array}{l}\text { Reason } \\
\text { adjustment }\end{array}$ & $\begin{array}{l}\text { Response } \\
\text { adjustment }\end{array}$ & \multirow[t]{2}{*}{$\mathrm{t}$} & \multirow[t]{2}{*}{$p$} \\
\hline & $\mathrm{M} \pm \mathrm{S}$ & $\mathrm{M} \pm \mathrm{S}$ & & & $\mathrm{M} \pm \mathrm{S}$ & $\mathrm{M} \pm \mathrm{S}$ & & \\
\hline Positive emotion & $2.91 \pm 0.53$ & $3.22 \pm 0.68$ & -8.32 & 0.000 & $3.13 \pm 0.63$ & $3.01 \pm 0.52$ & 3.67 & 0.000 \\
\hline Negative emotion & $2.98 \pm 0.49$ & $2.75 \pm 0.49$ & 8.06 & 0.000 & $2.89 \pm 0.44$ & $2.84 \pm 0.42$ & 2.95 & 0.003 \\
\hline
\end{tabular}

\subsection{Postgraduates Commit Suicide Attitude Differences in Demographic Variables Comparison}

Methods Using t test to analyze the commit suicide attitude variable and the demographic variable, that was particularly between F1, F2, F3, F4 and gender, and major, and grade using t test. The results showed that, in F3, the science students scored significantly lower than the arts students, $\mathrm{t}=2.78, p<0.01$. In F3, F4, high grade graduate students scored significantly lower than the low grade $(\mathrm{t}=2.20, p<0.05 ; \mathrm{t}=4.10, p<0.001)$, saw details in Table 3 .

\subsection{Correlation analysis of Positive, Negative Mood Regulation and Suicide Attitude of Postgraduates}

In the positive, negative mood, emotion regulation commit suicide on each dimension and attitude (F) and it's various dimensions were taken correlation analysis. Results display, in positive emotion, increased regulation (attention, catharsis regulating) significant positive correlation with F1 and F3, and significant negative correlation (Tang \& Huang, 2012), and attenuated (ignored regulation, regulation of inhibitory regulation) significant positive correlation with F3. In negative emotion regulation, attenuated significantly negatively correlated with F2. In suicide act attitude scores, ignoring the regulation and suppression of negative emotion regulation and F score was negatively related to positive, negative mood, saw details in Table 4.

\subsection{Multiple Stepwise Regression Analysis of Postgraduates' Emotion Regulation Effect on Commit Suicide Attitude}

The stepwise multiple regression analysis showed that suppressing negative emotion and avoiding positive emotion were important variables to affect graduate suicide attitude. See details in Table 5.

\subsection{Discussions}

In the aspect of emotion regulation, compared with the male postgraduate students, female postgraduates tended to use revealing emotion regulation. this was closely related to similar results of large groups of students' emotion regulation research, that was to say, girls adopt more reveling methods to regulate emotion. this difference might be related to gender roles in social expectations. Most people thought that male emotional was often viewed as lack of masculinity, cowardly, and female expression of emotion was the emotional performance by nature. As in the following, the social were more expect that men can control their emotion. The difference in grade was that low grade graduate students were more often to adopt emotion regulation than high grade. It was possible that the high grade graduate students participated in more social practice and suffered from more frustration and had more psychological endurance. So in the face of negative life events was less use of remorse, endure to attach great importance to the emotion, but a more sensible, more mature to deal with. When facing to negative emotion, postgraduate students adopted ignorance and suppress most among four types of emotion regulation (Xiao et al., 1999). However, when facing to positive emotion, attention and revealing appear more frequent. This showed that postgraduate students were tend to diminish facing to the negative emotion and tended to enhance facing to positive emotion. Moreover, in the positive and negative emotions, they were use reason regulation more. Postgraduate students were more likely ignored and pay attention to regulate their emotions.

In the attitude of commit suicide, according to the results of the survey, the post graduate students' attitude to the action of suicide, their own attitude, their family' attitude, the attitude of euthanasia and suicide attitude in general $(\mathrm{M}=2.92, \mathrm{~S}=0.28)$ was on the average between 2.5 a 3.5. This research was consistent with the results 
Table 3. Postgraduates commit suicide attitude differences in demographic variables comparison $(n=406)$.



Table 4. Correlation analysis of mood regulation and suicide attitude $(r, n=406)$.

\begin{tabular}{|c|c|c|c|c|c|c|}
\hline & & $\mathrm{F} 1$ & $\mathrm{~F} 2$ & F3 & $\mathrm{F} 4$ & $\mathrm{~F}$ \\
\hline \multirow{3}{*}{ Positive Emotion } & Ignore regulation & $-0.396^{* *}$ & 0.011 & $0.274^{* *}$ & -0.017 & $-0.145^{* *}$ \\
\hline & Suppressive regulation & -0.036 & 0.012 & $0.143^{* *}$ & -0.061 & 0.003 \\
\hline & Attention regulation & $0.161^{* *}$ & -0.094 & $-0.117^{*}$ & -0.078 & -0.020 \\
\hline \multirow[t]{2}{*}{0.036} & Catharsis regulation & $0.126^{*}$ & -0.096 & $-0.151^{* *}$ & -0.052 & -0.040 \\
\hline & Ignore regulation & $0.119^{*}$ & $-0.157^{* *}$ & $-0.203^{* *}$ & -0.079 & $-0.100^{*}$ \\
\hline \multirow{3}{*}{ Negative Emotion } & Suppressive regulation & -0.022 & $-0.121^{*}$ & -0.073 & $-0.167^{* *}$ & $-0.160^{* *}$ \\
\hline & Attention regulation & -0.025 & $-0.099^{*}$ & 0.036 & $-0.105^{*}$ & -0.094 \\
\hline & Catharsis regulation & $0.131^{* *}$ & 0.024 & -0.001 & -0.063 & 0.044 \\
\hline
\end{tabular}

Table 5. Stepwise regression analysis of Positive and negative emotion regulation impact on suicide attitude $(r, n=406)$.

\begin{tabular}{|c|c|c|c|c|c|c|c|c|}
\hline & $\begin{array}{l}\text { Depended } \\
\text { variable }\end{array}$ & Variables entered & $\begin{array}{l}\text { Unstandardized } \\
\text { coefficients }\end{array}$ & $\begin{array}{c}\text { Standardized } \\
\text { coefficients }\end{array}$ & Std. error & $\mathrm{t}$ & $p$ & $\mathrm{R}^{2}$ \\
\hline \multirow{7}{*}{$\begin{array}{l}\text { Negative } \\
\text { emotion }\end{array}$} & $\mathrm{F}$ & Suppressive regulation & -0.085 & -0.160 & 0.026 & -3.250 & 0.001 & 0.025 \\
\hline & \multirow{3}{*}{$\mathrm{F} 1$} & Ignore regulation & 0.131 & 0.184 & 0.042 & 3.139 & 0.002 & \multirow{3}{*}{0.037} \\
\hline & & Suppressive regulation & -0.149 & -0.153 & 0.058 & -2.256 & 0.011 & \\
\hline & & Catharsis regulation & 0.114 & 0.113 & 0.051 & 2.220 & 0.027 & \\
\hline & $\mathrm{F} 2$ & Ignore regulation & -0.085 & -0.157 & 0.027 & -3.187 & 0.002 & 0.025 \\
\hline & F3 & Ignore regulation & -0.135 & -0.203 & 0.032 & -4.172 & 0.000 & 0.041 \\
\hline & $\mathrm{F} 4$ & Suppressive regulation & -0.207 & -0.167 & 0.061 & -3.408 & 0.001 & 0.028 \\
\hline \multirow{6}{*}{$\begin{array}{l}\text { Positive } \\
\text { emotion }\end{array}$} & $\mathrm{F}$ & Ignore regulation & -0.060 & -0.145 & 0.020 & -2.952 & 0.003 & 0.021 \\
\hline & \multirow{2}{*}{$\mathrm{F} 1$} & Ignore regulation & -0.290 & -0.383 & 0.035 & -8.396 & 0.000 & \multirow{2}{*}{0.175} \\
\hline & & Attention regulation & 0.076 & 0.120 & 0.029 & 2.626 & 0.009 & \\
\hline & \multirow{3}{*}{ F3 } & Ignore regulation & 0.177 & 0.249 & 0.034 & 5.193 & 0.000 & \multirow{3}{*}{0.103} \\
\hline & & Catharsis regulation & -0.083 & -0.133 & 0.029 & -2.813 & 0.005 & \\
\hline & & Suppressive regulation & 0.068 & 0.099 & 0.033 & 2.070 & 0.039 & \\
\hline
\end{tabular}


of other scholars on College Students' attitude to commit suicide (Xin et al., 2010). That was means that postgraduate students hold contradictory or neutral attitude to commit suicide. However, the study found out that there were $6.2 \%$ of postgraduate students hold certainly, recognition, understanding and tolerant attitude to suicide. So when we inspected the graduate students' mental health, mental, we could not ignore this small group of people. We should make the greatest extent to prevent the occurrence of suicide. The inspection of each attitude on suicide found out that gender variable didn't reach significant difference on attitude of suicide in each dimension. this showed that it was important to interrupt male and female postgraduate students to suicide. Compared with the low grade, high grade postgraduate students showed more neutral or contradiction on the understanding of the families of suicide and euthanasia. this might be associated with low grade postgraduate students just stepped higher platform than the college students. They had a strong achievement motivation, and cherish the opportunity to pursuit life value. Therefore, they were more likely to show exclusion, discrimination against suicide attitude. Compared with the arts students, science students tended to more neutral or contradictory to the understanding of suicides' family. this result was not consistent with the previous research on college students. There was no significant difference on the different major college students' attitude to families of suicide and euthanasia. However, there were more college arts students hold positive and understanding attitude to action of suicide and attitude of suicide, while there were more college science students hold contradictory or neutral attitude to suicide. The specific reasons for the emergence of such differences needs further study.

Correlation analysis showed that, in positive emotion, the frequency of use emotion regulation (Attention regulation \& catharsis regulation) was positively correlated with F1 (attitudes toward suicide) and was negatively correlated with F3 (attitudes toward families of suicide). While weakening type regulation (ignore, suppress) was positively correlated with F3 (attitudes toward families of suicide) and only avoiding regulation was negatively correlated with F1. It's consistent with the result that avoiding regulation was negatively correlated with F (suicide attitude score), which showed that the regular use of rumination, revealing regulation of positive emotions tend to show negative suicide behavior, and showed understanding to families of suicide. On the contrary, postgraduate students who often used ignore and suppress regulation to adopt positive emotions were tending to show discriminatory attitudes. And repeatedly ignored regulation of positive emotions can enhance the tendency of suicide. In negative emotion, neglect, catharsis regulation was positively correlated with F1, and neglect, inhibition, rumination emotional regulation showed a significant negative to F2 (attitudes to suicide). Neglect emotional regulation was negatively correlated with F3, and inhibition, rumination motional regulation was negatively correlated with F4 (attitudes toward euthanasia). But neglect and inhibition was positively correlated with F. this showed that postgraduate students who often used ignored, catharsis regulating showed negative suicide behavior (Cui et al., 2012). Postgraduate students who often ignored regulating negative emotion show recognition, understanding attitudes to of families of suicide and who often were suppressed and pay attention to regulating negative emotion tend to recognize and tolerance to opinion to suicide behavior and attitude of euthanasia. And suppressing type regulating negative emotion would increase the possibility of postgraduate students to suicide with positive attitude. stepwise multiple regression analysis further inspection found that, in the positive and negative emotion, when respectively predicted the attitude and dimensions of suicide, only in positive emotion had not variable in the F2, F4 regression equation. Other predictor variables were variables into the regression equation. However, the regression coefficient (b) and coefficient of determination (R2) were very small. this was similar to other exploration of suicide attitude factors. The majority of R2 was small, which showed that the suicide attitude was determined by many factors, and was not influenced by single factoremotion regulation. The regression equation showed that different predictor variables had different entering variable. The prediction of the suicide attitude score showed that, ignore the regulation of positive emotion, inhibitory regulation of negative emotion was an important factor affecting postgraduate students' suicide attitude.

\section{Conclusion}

In summary, as a highly educated population, postgraduate students' emotional regulation was consistent with the results of Miner Huang, Dejun Guo, Xiangjun Cui, Chunjie Lu and other scholars' research on "University Students' Emotion Regulation Types". In the suicide attitude, there were differences between the research and conclusion of Shuiyuan Xiao, Yongqing Tang, Hong Yang and other scholars' survey on "College Students Attitude toward Suicide". Postgraduate students adopted attention more often catharsis regulation of positive emotion; they adopted more neglect and suppression of regulating negative emotion, while ignoring the regulation of 
positive emotion; inhibitory regulation of negative emotion was an important factor affecting post graduate students' suicide attitude. The requirements of school mental health workers popularized mental health knowledge and paid attention to guide postgraduate exclusion of positive and negative emotional neglect, and inhibition, then took appropriate and timely manner to vent their emotions, and reached the aim of students' prevention and intervention to postgraduate suicide (Shi et al., 2011).

However, the limitations of the present research mainly included the number of participants which was less and the regional range which was narrow, subjects with an average age of 25 that was not on behalf of the other age groups of highly educated groups, and the limitations of questionnaire investigation leading to the results of the study which could not effectively cause analysis and interpretation. So, the future research trends should choose large-scale, more areas to do the questionnaire, more to consider the characteristics of subjects, including age, job, family status, etc., on this basis, designing operational situation, carried on the experimental and longitudinal study.

\section{References}

Chiles, J. A., \& Strosahl, K. D. (1995). The Suicide Patient: Principles of Assessment, Treatment, and Case Management. Washington, DC: American Psychiatric Press.

Cui, X.-J., Lu, C.-J.,Guo, Y.-F. et al. (2012). The Relationship betwcen Emotion Regulation and Depression of College Students. China Journal of Health Psychology, 3, 431-432.

Gross, J. J. (2002). Emotion Regulation: Affective, Cognitive, and Social Consequences. Psychophysiology, 39, $281-291$. http://dx.doi.org/10.1017/S0048577201393198

Han, L., \& Zhang, Yan. (2014). Effects of Social Support and Resilience on Suicide Ideation among College Students. Chinese Journal of School Health, 1, 51-53.

Huang, M.-E., \& Guo, D.-J. (2000). The Essence of the Emotion Regulation. Psychological Science, 1, 109-110.

Jing, C.-X., Wang, S.-Y., Yang, G. et al. (2008). Attitudes towards Suicide among Undergraduates and Its' Influencing Factors. Chinese Journal of Public Health, 8, 913-914.

Liu, Y.-J., Han, L.-J., \& Wang, Y.-J. (2011). Research on Relation between Social Support and Undergraduates' Suicide Attitude. Journal of Tangshan Teachers College, 1, 139-142.

Luo, J.-B. et al. (2004). College Students' Suicide Attitude and Suicide Ideation and the Investigation of the Life Events and the Way to Deal With. Chinese Medical Ethics, 2, 57-59.

Shi, Y.-F. et al. (2011). Study of Graduate Student Suicide Attitude, Coping Styles and Social Support Situation. Science \& Technology Information, 8, 80-81.

Tang, G.-Q., \& Huang, M.-E. (2012) Diverse Consequences of Negative Emotional Responses Between High and Low Happiness People. Acta Psychologica Sinica, 8, 1086-1099.

Thompson, R. A. (1991). Emotion Regulation and Emotion Development. Educational Psychological Review, 3, $269-307$. http://dx.doi.org/10.1007/BF01319934

Wang, B.-W. (2012). An Analysis of Relationship of Suicide Attitude, Mental Health \& Personality Traits in University Students. Theory and Practice of Education, 21, 37-39.

Xiao, S. Y., Yang, H., \& Dong, Q. H. et al. (1999). The Development, Reliability and Validity of Suicide Attitude Inventory. Chinese Mental Health Journal, 4, 250-251.

Xie, X. L., Zou, B., \& Huang, Z. Y. (2012). Relationships between Suicide Attitudes and Perception of Life Purpose and Meaning of Life in College Students. Journal of Southern Medical University, 10, 1482-1485.

Xin, Y., Li, H., \& Yuan, J.-J. (2010). Negative Emotion Interferes with Behavioral Inhibitory Control: An ERP Study. Acta Psychologica Sinica, 3, 334-341. 